\title{
Positive Disposition in the Prediction of Strategic Independence among Millennials
}

\author{
Robert Konopaske *, Eric G. Kirby and Susan L. Kirby \\ Department of Management, Texas State University, San Marcos, TX 78666, USA; ek10@txstate.edu (E.G.K.); \\ sk10@txstate.edu (S.L.K.) \\ * Correspondence: rkonopaske@txstate.edu
}

Received: 14 September 2017; Accepted: 14 November 2017; Published: 20 November 2017

\begin{abstract}
Research on the dispositional traits of Millennials (born in 1980-2000) finds that this generation, compared to earlier generations, tends to be more narcissistic, hold themselves in higher regard and feel more entitled to rewards. The purpose of this intragenerational study is to counter balance extant research by exploring how the positive dispositional traits of proactive personality, core self-evaluation, grit and self-control predict strategic independence in a sample of 311 young adults. Strategic independence is a composite variable measuring a person's tendency to make plans and achieve long-term goals. A confirmatory factor analysis and hierarchical regression found evidence of discriminant validity across the scales and that three of the four independent variables were statistically significant and positive predictors of strategic independence in the study. The paper discusses research and practical implications, strengths and limitations and areas for future research.
\end{abstract}

Keywords: strategic independence; proactive personality; grit; core self-evaluation; self-control; careers; transition; Millennials

\section{Introduction}

Over the past 15 years there has been a considerable amount of research conducted on how young adults differ from members of previous generations regarding their dispositional traits, work values, attitudes, as well as work-life balance and career choices (cf., Lyons and Kuron 2014). When examining personality research, a clear pattern emerges; namely, much of the extant research on young adults seems to focus more intently on their negative traits. For example, Twenge and Campbell (2008) report that when compared to individuals at the same age in earlier decades, young people today (a cohort they label 'Generation Me') possess higher levels of narcissism, depression, anxiety and self-esteem; exhibit more external locus of control; and, have a lower need for social approval. Additionally, Miller and Konopaske (2014) find that Machiavellianism in young adults relates positively to work entitlement. Additionally, Byrne et al. (2010) report that young adults with high levels of trait entitlement are less likely to experience increased job satisfaction despite being the recipients of more favorable human resource management practices.

The popular press has reinforced some of the aforementioned negative traits associated with young adults and their inability or unwillingness to enter fully into adulthood. A sample of recent headlines includes: "Where Have All the Grownups Gone? Why 'Adulthood' As We Know It Is Dead" (Henderson 2014), “We Millennials Lack a Roadmap to Adulthood" (Stafford 2015) and "Millennials' Job Struggles: A Sign of Delayed Adulthood in the New Economic Reality" (Freeman 2013).

Rather than continuing to focus on the negative dispositions associated with young adults (Byrne et al. 2010; Miller and Konopaske 2014; Twenge and Campbell 2008), this paper focuses on how positive dispositional traits influence Millennials. Additionally, the study addresses other gaps in the extant personality research literature such as building understanding of the under researched nomological network of the antecedents of strategic independence. 


\section{Nomological Network}

A nomological network is an important tool for building evidence of construct validity in social science research studies. According to the seminal article by Cronbach and Meehl (1955, p. 290) Cronbach and Meehl "Learning more about' a theoretical construct is a matter of elaborating the nomological network in which it occurs, or of increasing the definitiveness of the components." These authors also state: "An enrichment of the net such as adding a construct or a relation to theory is justified if it generates nomologicals that are confirmed by observation..." (Cronbach and Meehl 1955, p. 290). Other researchers suggest that construct validation is also the process of identifying constructs by developing measures of those constructs and examining relations between the various measures (Binning and Barrett 1989).

The nomological network in the present study consists of a criterion variable, strategic independence, as well as four positive disposition predictor variables, including proactive personality, core selfevaluation, grit and self-control. Strategic independence is defined as one's propensity of make and adhere to plans to achieve long-term goals (Kirby et al. 2016). It is a compound trait comprised of achievement striving and planfulness. In previous research, achievement striving has been found to predict positive employee outcomes such as commitment (Moon 2001), leadership emergence (Marinova et al. 2013) and supervisory ratings of potential and overall job and task performance (Thomason et al. 2011). The other trait component that comprises strategic independence, planfulness, has been found to predict positive student outcomes. Savickas, Briddick and Watkins (2002) reported that college students who possess planful competence in career development are more likely to realize their potential.

The present study's four predictor variables have been used in different combinations to study positive employee and student outcomes. For example, proactive personality and core self-evaluation have been reported to relate positively to such outcomes as job engagement, employee task performance and affective organizational commitment (Haynie et al. 2017), work-school enrichment (McNall and Michel 2011) and negatively related to turnover intentions (Joo et al. 2015). In addition, self-control and proactive personality were found to predict extrinsic career success (salary and occupational prestige) through educational attainment (Converse et al. 2012). In a different study, Duckworth and Gross (2014) found that the two personality traits, grit and self-control, are strongly correlated but operate in different ways over different time horizons.

\section{Conceptual Foundation and Hypotheses}

\subsection{Strategic Independence}

Strategic independence, the criterion variable in this study, is defined as one's propensity to make and adhere to plans to achieve long-term goals (Kirby et al. 2016). Studying this trait is important because young people are increasingly experiencing a "prolonged identity exploration" (Mechler and Bourke 2011) that is thought to contribute to the delay of reaching such hallmark achievements of adulthood as starting families, finishing college, obtaining financial independence and launching careers (Arnett 2007). This 'failure to launch' phenomenon, coupled with record levels of underemployment, encourages us to develop our understanding of the issues surrounding young adults' dispositions to move forward (by traditional standards) with their lives.

To deepen the understanding of strategic independence, we will discuss the two traits of which it is comprised: achievement striving and planfulness. Utilizing the compound trait approach where traits are blended into a composite for research purposes (Fein and Klein 2011; Wanberg and Banas 2000), the achievement striving component of conscientiousness and planfulness are combined to form the criterion in this study, strategic independence (Kirby et al. 2016).

While scant research has explored which constructs predict strategic independence, a recent study found that this construct was a significant and positive predictor of entrepreneurial orientation among young adults (Kirby et al. 2016). The current study builds on narrow-band trait research by focusing 
on one facet of conscientiousness, achievement striving (Costa and McCrae 1992), which is a dimension of strategic independence. There is strong emerging support in the personality research literature for studying underlying facets associated with conscientiousness in the prediction of job performance and other positive achievement outcome variables (Marinova et al. 2013; Thomason et al. 2011). Achievement striving is defined as having high levels of aspiration, willingness to work hard to achieve goals, purposefulness and a sense of direction in life (Costa and McCrae 1992).

Barrick and Mount (1991, p. 18) describe the achievement side of conscientiousness as tapping traits such as "planful, organized, persistent and hardworking." According to Marinova et al. (Marinova et al. 2013, p. 1262): "Individuals high in achievement striving set high goals for themselves and tend to persist in those goals." Recent research has explored the degree to which achievement striving relates to performance and leadership criteria. For example, Thomason et al. (2011) report that achievement striving relates positively to supervisors' evaluations of the managerial potential of employees. Ziegler et al. (2009) examine the extent to which achievement striving moderates the impact of intelligence on academic performance. These researchers find that achievement striving increased the performance of low performers and buffered the output of the high performers (Ziegler et al. 2009).

The second dimension of strategic independence is planfulness. A component of the California Psychological Inventory (CPI), planfulness is an appropriate construct to build understanding of the predispositions of young adults as they plan to transition from college to careers and adulthood. Planfulness assesses an individual's need for achievement in structured situations such as college and captures the degree to which an individual is organized, efficient, foresighted, productive, thorough, persevering and seen by others as capable and reliable (Gough 1995).

Based on prior research, we theorize that strategic independence will not remain static throughout a person's work life. According to the Motivational Theory of Life-Span Development, people will continue to develop new and refined approaches for striving to achieve their goals throughout their lives (Heckhausen et al. 2010). As they face obstacles and failures, they will learn to adapt to their changing situations. Individuals will learn to adapt by both developing coping mechanisms and learning to thrive (Hall 2012). In addition, planfulness is associated with career success (Lapan 2004). Drawing upon Life-career Development Theory, Kenny et al. (2006) found that as counselling, training and mentoring increase an individual's planfulness, work engagement also increases. Therefore, we expect that strategic independence will increase as a person ages and faces work and non-work challenges throughout his/her life. As a person matures, develops and faces challenges, s/he learns to better make and adhere to long-term goals. In other words, 'failure to launch' is more likely a product of youthful inexperience than a dispositional trait.

To better understand the propensity to make plans and achieve long-term goals, it is necessary to investigate its relationship to other personality variables. Specifically, we are interested in discovering the impact of four positive dispositional traits on Millennials' strategic independence. These traits are proactive personality, core self-evaluation, grit and self-control.

\subsection{Predictor Variables}

Proactive personality. The current paper builds on this previous research with the goal of learning more about the linkage between proactive personality and Millennials' predispositions toward making plans and transitioning from college life to careers. Drawing on interactionism theory that suggests that behavior is both internally and externally controlled, Bateman and Crant (1993) define the prototypical proactive personality as someone who is relatively unconstrained by situational forces and seeks to effect environmental change. These researchers suggest "Proactive people scan for opportunities, show initiative, take action and persevere until they reach closure by bringing about change" (Bateman and Crant 1993, p. 105). Research finds that proactive personality is positively related to a variety of individual and work-related outcomes (Bateman and Crant 1993). Fuller and Marler (2009) report that proactive personality positively relates to such outcome variables as objective and subjective career success, job performance, taking charge and career self-efficacy. 
Additionally, Seibert et al. (2001) find that proactive personality exerts a positive influence on career initiative that, in turn, impacts career progression and satisfaction.

What has yet to be determined is how young adults' proactive personality relates to strategic independence (achievement striving and planfulness), regarding their transition from college to career. Specifically, we are interested in whether proactive young adults exhibit a greater propensity towards making plans and seeing them through. Taken together, this study hypothesizes the following:

Hypothesis 1 (H1). Proactive personality will be positively related to strategic independence.

Core self-evaluation. Another personality trait that may influence young adults' strategic independence is core self-evaluation (CSE), which is defined as "one's worthiness, effectiveness and capability as a person" (Judge et al. 2003, p. 304). Judge and Hurst (2007) argue that CSE is a broad, higher order trait comprised of four personality traits: self-esteem (the overall value one places on oneself as a person); locus of control (the way one attributes causes of events in life); neuroticism (the tendency to focus on and exhibit negative effects such as hostility and fear) and, generalized self-efficacy (the judgment of how successfully one can perform across various situations). In a review of the CSE literature, Chang et al. (2012) find meta-analytic support for the relation of CSE with various outcomes, including job and life satisfaction, work commitment, motivation and in-role and extra-role job performance.

We aim to expand on these findings by exploring how the level of CSE in Millennials might predict their levels of strategic independence. Considering the evidence that CSE has a direct effect on predicting young adults' future income and work success (Judge and Hurst 2007), we submit that young adults in college with high levels of CSE would be oriented toward making and persisting with plans to achieve important goals. For most college students, a major goal is to navigate the college-career transition by planning for and achieving a successful career-launching position upon graduation. Thus, existing empirical research on the relations between CSE and individual personality differences, combined with the evidence that CSE among Millennials is important predictor of planning and career success, lead us to propose the following:

Hypothesis 2 (H2). Core self-evaluation will be positively related to strategic independence.

Grit. Grit is a trait that is increasingly seen as an important component of success due to an individual's perseverance and commitment to long-term goals (Duckworth et al. 2007; Tough 2013) and includes "working assiduously toward a single superordinate goal ... " (Duckworth 2015, p. 1). While this trait is correlated with well-established predictors of success like conscientiousness and mental ability, grit has been found to demonstrate incremental validity beyond these constructs when predicting educational and career success (Duckworth et al. 2007). Other researchers report similar findings that grit explains additional variance in success beyond that of mental ability and conscientiousness. For example, Abuhassan and Bates (2015) find that grit is associated with higher life-course accomplishment. Bowman et al. (2015) report that perseverance of effort is related to academic performance and satisfaction. These researchers find that consistency of effort is inversely related to subjects' intent to change majors and alter careers. In other words, grit is positively associated with the ability to set long-term goals and work toward seeing them through to conclusion. Therefore, we propose the following:

Hypothesis 3 (H3). Grit will be positively related to strategic independence.

Self-control. Self-control is also an important construct in predicting several positive individual outcomes. Duckworth and Allred (2012) report that self-control is an important predictor of educational achievement, health and social outcomes from preschool to early adulthood. Within the domain of personality psychology, self-control is defined as the voluntary regulation of behavioral, emotional and 
attentional impulses when presented with immediate temptations (Duckworth et al. 2007). The results of a recent meta-analysis suggest that self-regulation, another form of self-control, predicts goal achievement (Burnette et al. 2013). Therefore, it can be argued that Millennials who possess high levels of self-control will be more likely to make plans and stay focused on long-term goals while avoiding short-term impulses and distractions. Thus, we propose the following hypothesis:

Hypothesis 4 (H4). Self-control will be positively related to strategic independence.

Figure 1 illustrates this paper's conceptual model.

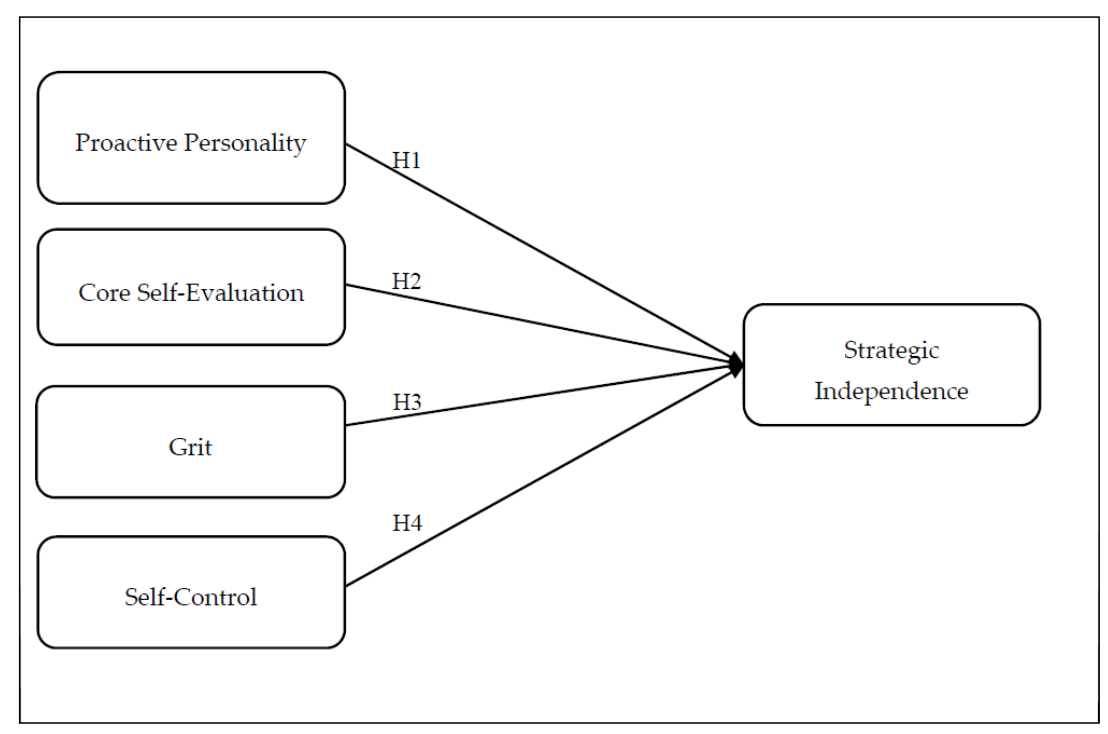

Figure 1. Conceptual model.

\section{Research Methods}

\subsection{Procedure and Sample Participants}

A cross-sectional research design was used which consisted of administering a paper and pencil, self-report questionnaire to a total of 672 business students enrolled in three upper level undergraduate management courses at a large southwestern university. Millennial college students are an appropriate sample for the current study given their age and near universal desire to make a successful transition from college to careers upon graduation. The confidentiality of each respondent was protected by administering an informed consent form separate from the survey. Participation was voluntary and a nominal amount of extra credit was provided to students in exchange for completing the questionnaire. Of the total number of students who were given the opportunity to participate, 505 completed the questionnaire for a response rate of 75.1 percent. In terms of quality control, we removed subjects from the study that were born before 1980 and thus did not fit within the Millennial generation. Also, we removed subjects that failed to provide complete answers to all the scales in the survey. This step resulted in our using 311 questionnaires in the analysis.

The sample participants' ages ranged from 18-32 with a mean age of 22 years. Forty-eight percent of respondents were female. Respondents' self-reported racial and ethnic categories were: 57.4\% Caucasian, 27.1\% Hispanic, 6.5\% African American, 2.6\% Asian and 6.4\% other.

\subsection{Measures}

Strategic independence. Strategic independence was measured by combining two narrow-band traits: (1) the 15-item achievement striving facet of conscientiousness from the Revised NEO Personality Inventory (Costa and McCrae 1992); and (2) the 10-item planfulness (IPIP version of the Achievement 
via Conformance Ac) subscale (Gough 1996). The California Psychological Inventory (CPI) is used by researchers to "assess attributes of personality relevant to behavior in everyday settings such as school, work, the family and relationships to peers" (Gough and Lanning 1986, p. 205). It is used in a variety of research studies, including understanding more about the relationships between high school and college students' scores on the CPI and their academic performance (Gough 1985). Other CPI-related research explores how scores on the CPI relate to individuals' career choices and decisions (Bartnick et al. 1985) and career profiles (Gough 1995). Data were gathered from respondents using a 7-point Likert type response scale $(1=$ 'never' to $7=$ 'always'). Sample items include: 'I stick to my chosen path' and 'I go straight for the goal.' Cronbach's alpha reliability coefficient for scores on this compound trait scale was 0.91 .

Proactive personality. The 17-item Proactive Personality Scale (Bateman and Crant 1993) was used to measure this construct. Data were gathered from respondents using a 7-point Likert response scale $(1=$ 'strongly disagree' to $7=$ 'strongly agree'). Sample items include: 'I enjoy facing and overcoming obstacles to my ideas' and 'I tend to let others take initiative to start new projects' (reverse scored). Cronbach's alpha reliability coefficient was 0.90 .

Core self-evaluation (CSE). CSE was measured with the 12-item Core Self-evaluation Scale (Judge et al. 2003). Data were collected from participants via a five-point Likert response scale anchored by $1=$ 'strongly disagree' and $5=$ 'strongly agree.' Sample items include: 'Overall, I am satisfied with my life' and 'Sometimes when I fail I feel worthless' (reverse scored). The reliability coefficient for scores on this scale was 0.84 .

Grit. To measure grit, the 12-item Grit Scale was used from Duckworth et al. (2007). When collecting data from participants, a 5-item Likert type response scale was used anchored by $1=$ 'not like me at all' and $5=$ 'very much like me.' Two sample items include: 'I have overcome setbacks to conquer an important challenge' and 'I have been obsessed with a certain idea or project for a short time but later lost interest' (reverse scored). Cronbach's alpha reliability coefficient was 0.69.

Self-control. Self-control was measured with the 13-item Self-Control Scale (Tangney et al. 2004). Data were collected from respondents using a 5-point Likert type response scale ( 1 = 'not like me at all' to $5=$ 'very much like me'). Sample items include: 'I am good at resisting temptation' and 'I blurt out whatever is on my mind' (reverse scored). The Cronbach's alpha reliability coefficient for this scale was 0.82 .

Control variables. Social desirability is an attempt to manipulate how one is perceived by others; which could ultimately lead to response distortion (Paulus 1986). Personality assessments may be especially vulnerable to faking given the possibility that " ... in many contexts (e.g., personnel selection), test takers' motives may not be genuinely objective when responding to a personality inventory" (Smith and Ellingson 2002, p. 211). One way to protect against common method variance is to separate the effects of social desirability from the variables under study. To statistically control for social desirability, this study used the 13-item Marlowe-Crown Form C (M-C Form C). Reynolds (1982) finds that this short form shows acceptable evidence of reliability and validity. In the current study, data are gathered from respondents using a true or false response scale. Item scores are summed so that a respondent's scores vary from 0-13. Sample items include: 'I sometimes feel resentful when I don't get my way' and 'No matter who I'm talking to, I'm always a good listener.' Cronbach's alpha for scores on this scale was 0.70 . Other control variables in the study included age (in years), gender $(0=$ female, $1=$ male $)$ and minority status $(0=$ non-Hispanic Caucasian and $1=$ all others $)$. We combined ethnic or racial categories (i.e., African American, Hispanic American, Asian American, Native American, or Other) into minority status due to the low number of respondents in all but the Hispanic American group.

\subsection{Data Analysis}

Each scale-level score was calculated as the average of all item-level responses for that measure. Bivariate correlations were computed between each scale score. Given that most of the scales 
would likely be correlated with one another, a confirmatory factor analysis was conducted to assess the reliability of the scales in the study (Jöreskog and Sörbom 2006; Long 1983). A hierarchical regression analysis was used to examine the bivariate relationships while controlling statistically for the impact of the other variables in the model. Effect sizes for each variable were computed as squared semi-partial correlations.

\section{Results}

\subsection{Correlations}

Table 1 presents means, standard deviations and correlation coefficients for the variables in the study. Multiple measures of different elements of the same phenomenon are important for improved construct validity; however, they are frequently intercorrelated with one another. However, the range of values of variance inflation factor (VIF) for our variables was 1.04 to 1.77, which is well below the threshold of 5.3 used for the detection of multicollinearity (Hair et al. 1995, p. 127).

Table 1. Descriptive Statistics and Zero-Order Correlations.

\begin{tabular}{|c|c|c|c|c|c|c|c|c|c|c|}
\hline & Mean & S.d. & 1. & 2. & 3. & 4. & 5. & 6. & 7. & 8. \\
\hline 1. Strat. Ind. & 4.80 & 0.62 & & & & & & & & \\
\hline 2. Gender & 0.48 & 0.50 & -0.02 & & & & & & & \\
\hline 3. Age & 21.76 & 2.29 & 0.09 & $0.32^{* *}$ & & & & & & \\
\hline 4. Min. Status & 0.38 & 0.49 & $0.16^{* *}$ & -0.04 & -0.05 & & & & & \\
\hline 5.Soc. Des. & 6.02 & 2.88 & $0.32^{* *}$ & 0.01 & $0.14^{*}$ & $0.18^{* *}$ & & & & \\
\hline 6. Pro. Person. & 5.40 & 0.73 & $0.59^{* *}$ & 0.07 & 0.06 & $0.23^{* *}$ & $0.22^{* *}$ & & & \\
\hline 7. Core Self-Evl. & 3.73 & 0.61 & $0.40^{* *}$ & $0.15^{* *}$ & $0.18^{* *}$ & 0.11 & $0.30^{* *}$ & $0.36^{* *}$ & & \\
\hline 8. Grit & 3.76 & 0.47 & $0.63^{* *}$ & 0.03 & $0.15^{* *}$ & $0.20^{* *}$ & $0.37^{* *}$ & $0.40^{* *}$ & $0.51^{* *}$ & \\
\hline 9. Self-control & 3.17 & 0.65 & $0.58^{* *}$ & 0.00 & $0.13^{*}$ & $0.13^{*}$ & $0.43^{* *}$ & $0.34^{* *}$ & $0.43^{* *}$ & $0.55^{* *}$ \\
\hline
\end{tabular}

Note: $n=311$; S.d. $=$ standard deviation. Gender was coded $0=$ female and $1=$ male. Minority status was coded $0=$ non-Hispanic Caucasian and $1=$ all others. ${ }^{*} p<0.05 .{ }^{* *} p<0.01$.

\subsection{Confirmatory Factor Analysis}

Prior to testing our hypotheses, we conducted confirmatory factor analyses (CFA) on our variables using LISREL 8.80 (Jöreskog and Sörbom 2006). We conducted these analyses to determine whether the expected factor structure could be produced and to demonstrate the discriminant validity of scores on our scales. The measurement model consisted of six factors, one for each of our scales: social desirability, proactive personality, CSE, grit, self-control and strategic independence. All items in the six-factor model were not overly skewed or kurtotic with skewness values ranging from -1.85 to 1.30 and kurtosis values ranging from -2.01 to 4.60 . West et al. (1995) suggest avoiding variables with a univariate skewness index in excess of $|2.0|$ and a univariate kurtosis more than $|7.0|$. Rules of thumb regarding acceptable fit suggest that comparative fit index (CFI) values should be equal to or greater than 0.90 (Kline 2000). Browne and Cudeck (1993) suggest that root mean square error of approximation (RMSEA) values of 0.08 and lower represent reasonable fit. Standardized root mean square residual (SRMR) values should be below 0.08 (Hu and Bentler 1999). The fit indices for this model were $\chi 2(3554)=6791.04, \mathrm{CFI}=0.92, \mathrm{SRMR}=0.08, \mathrm{RMSEA}=0.06$, thus demonstrating acceptable fit.

Next, a one-factor model that forced all items from the six scales onto a single factor was analyzed. The one-factor model CFA model did not fit the data well. The chi-square value was $8685.78(\mathrm{df}=3569$, $p<0.001$ ) and the CFI, SRMR and RMSEA were worse than the 6-factor model with values of 0.88 , 
0.85 and 0.09 , respectively. The change in chi-square test of the nested model (one-factor vs. six-factor models) resulted in a statistically worse fit. The $\chi 2$ value was $1894.74(d f=15, p<0.001)$. These findings suggest that the one-factor model did not fit the data as well as the six-factor model. Consequently, common method variance is only a very slight possibility and not likely to be contaminating the interpretation of the findings in the current study (Podsakoff et al. 2012).

\subsection{Hierarchical Regression Analysis}

To assess the impact of the independent variables on strategic independence, hierarchical regression analysis was conducted. This technique was used to assess the impact of the predictor measures on strategic independence over-and-above the effects of the control variables. First, the control variables of age, gender, minority status and social desirability were entered into the initial equation. Next, the independent measures of proactive personality, core self-evaluation, grit and self-control were entered into the second block of the regression model.

The results of the hierarchical regression equations testing the four hypotheses are shown in Table 2. As can be seen in Step 1, the $F \Delta$ value in the model is significant $(p<0.01)$ and the control variables explain 12 percent of the overall variance $\left(R^{2}\right)$ of strategic independence. In Step 2, the $F \Delta$ value in the model is significant, indicating that the block of predictor variables significantly improves the explanatory power over Step 1 (control variables) and the full model explains 60 percent of the overall variance $\left(R^{2}\right)$ in strategic independence. In terms of individual predictor variables in Step 2, proactive personality, grit and self-control are all positive and statistically significant, thus supporting Hypotheses 1, 3 and 4. However, the effect for core self-evaluation was not significant, thus failing to support Hypothesis 2.

Table 2. Results of Hierarchical Regression Analysis for Predictors of Strategic Independence.

\begin{tabular}{|c|c|c|c|c|c|c|}
\hline \multirow{2}{*}{ Variables } & \multicolumn{3}{|c|}{ Step 1 (Controls) } & \multicolumn{3}{|c|}{ Step 2 (Independents) } \\
\hline & B & S.E. & $\beta$ & B & S.E. & $\beta$ \\
\hline Constant & 4.01 & 0.33 & & 0.79 & 0.29 & \\
\hline Gender & -0.04 & 0.07 & -0.04 & -0.06 & 0.05 & -0.05 \\
\hline Age & 0.02 & 0.02 & 0.06 & 0.00 & 0.01 & 0.00 \\
\hline Minority status & 0.14 & 0.07 & $0.11 *$ & -0.04 & 0.05 & -0.03 \\
\hline Socially desirable responses & 0.06 & 0.01 & $0.30 * *$ & 0.00 & 0.01 & 0.01 \\
\hline Proactive personality & & & & 0.32 & 0.04 & $0.38^{* *}$ \\
\hline Core self-evaluation & & & & -0.03 & 0.05 & -0.03 \\
\hline Grit & & & & 0.47 & 0.07 & $0.35 * *$ \\
\hline Self-control & & & & 0.27 & 0.04 & $0.28^{* *}$ \\
\hline F-score (df1, df2) & & $10.42(4,306) * *$ & & & $88.46(8,302) * *$ & \\
\hline$\Delta$ F-score & & $10.42 * *$ & & & $78.04 * *$ & \\
\hline$R^{2}$ & & 0.12 & & & 0.60 & \\
\hline$\Delta R^{2}$ & & 0.12 & & & 0.48 & \\
\hline Adjusted $R^{2}$ & & 0.11 & & & 0.58 & \\
\hline
\end{tabular}

Note: Gender was coded $0=$ female and $1=$ male. Minority status was coded $0=$ non-Hispanic Caucasian and $1=$ all others. $\mathrm{N}=311 .{ }^{*} p<0.05 .{ }^{* *} p<0.01$.

\section{Discussion}

This study investigated how more narrowly conceptualized and positive dispositional traits of proactive personality, CSE, grit and self-control relate to young adults' dispositions toward strategic independence. Proactive personality was a statistically significant predictor of strategic independence, thus supporting Hypothesis 1. This finding is in line with previous research reporting that employees' proactive personality is linked to objective and subjective career outcomes and career initiative-taking (Fuller and Marler 2009; Seibert et al. 2001). This positive trait was also found to predict college students' job search success (Brown et al. 2006). Young adults in college who are proactive will be more inclined to make and adhere to long-term plans such as transitioning successfully from college into promising early careers. 
Contrary to the study's expectations, core self-evaluation was not related to strategic independence in this study. Therefore, Hypothesis 2 was not supported. While previous research found that CSE predicted initial work success and other career-related outcomes among adolescents and young adults (Judge and Hurst 2007), CSE did not predict young adults' propensity for planning and achievement striving in the current study. We suspect the lack of statistical significance is due to methodological rather than theoretical issues. It is possible that one or more of the other predictor variables is obscuring the variance in the criterion explained by CSE. Referring to Table 1, the bivariate correlation between core self-evaluation and strategic independence was statistically significant at $0.40(p<0.01)$. However, in Model 2 of the regression analysis, CSE was not a significant predictor of the outcome variable. It is possible that the independent variable, self-control, overlapped with the locus of control trait of CSE, thus obscuring the variance potentially explained by CSE in strategic independence.

Another disposition in this study, grit, was positively related to strategic independence, thereby supporting Hypothesis 3. This finding suggests that young adults in college who possess grit are more inclined to be strategically independent than those with lower levels of this trait. As a predictor of myriad success outcomes related to careers (Duckworth and Allred 2012) and academic success (Bowman et al. 2015), grit is a critical factor for setting and achieving long-term goals that require perseverance and tenacity. For many college students nearing graduation grit may be an essential ingredient for motivating them to make and sustain their commitment to plans that will help them transition successfully into their careers.

Finally, Hypothesis 4 was supported. Self-control exerted a positive influence over young adults' strategic independence. This outcome aligns with findings from previous research that self-control relates positively to career and academic success (Duckworth and Allred 2012) and negatively to procrastination (Converse et al. 2012). Young adults with high levels of self-control are more inclined to make and adhere to plans in order to achieve long-term goals like landing a quality early career position upon graduation from college.

In sum, three of the four hypotheses in the study were supported, indicating a significant positive relationship between well-established positive dispositional traits and the relatively new personality construct of strategic independence. The ability of Millennial college students to make and stick to long-term plans is impacted by their ability to exhibit proactivity, grit and self-control. Strategic independence is positively related to one's ability to show initiative and act, remain focused and overcome distractions and persevere in the face of obstacles.

The current study contributes to research on individual personality differences in a variety of ways. First, it builds understanding of how positive dispositional traits in Millennials predict strategic independence, which is an important outcome related to making a successful college to career transition. Building the nomological network surrounding strategic independence is critical to better understand how young adults can successfully transition for college to career. To the best of our knowledge no other researchers have studied this relationship. Of those who have studied personality traits of young adults, much of the extant research has focused on negative traits (Byrne et al. 2010; Miller and Konopaske 2014; Twenge and Campbell 2008). As Millennials take on a greater role in business and society, it is important to understand the impacts of both positive and negative traits on important outcome variables like strategic independence.

Another contribution to research is the demonstrated usefulness of strategic independence. This trait, with its components of achievement striving and planfulness, is a parsimonious construct that builds understanding of what it takes for young adults to transition out of college and into early careers (Kirby et al. 2016). Millennials with high levels of strategic independence are less likely to be perceived in the negative light cast by much of the dispositional research to date since they will serve as positive illustrations and role models of their generation.

A key strength of the current study is its use of validated measures of several of the constructs, including proactive personality, core self-evaluation, grit and self-control. However, like all research the current study has limitations. To mitigate the risk of common method variance, we followed 
several of the a priori remedies offered by Podsakoff et al. (2012) to reduce respondents' motivation to respond stylistically such as including scales with positively- and negatively-worded items, varying the scale types and using different anchor labels. Additionally, to "overcome the limiting assumptions underlying coefficient alpha" (Judge and Bretz 1994, p. 43), CFA was used to assess the reliability of the six-factor measurement model, which resulted in an acceptable fit. The risk of social desirability bias was addressed by making the questionnaires confidential and controlling statistically with the Marlowe-Crown social desirability scale (Reynolds 1982). Even with these controls in place, cross-sectional, single-source research designs reduce the ability to infer causality, which could be addressed in future research by employing longitudinal and qualitative approaches to data collection. Also, researchers can take additional steps to diminish method bias by separating temporally the measurement of the predictor and criterion variables and using multiple sources (e.g., professors and advisors and supervisors at work) from which to collect data (Podsakoff et al. 2012).

Future research could also expand on the current paper's model by exploring the direct effects of these predictor variables and strategic independence on career-behavioral outcomes such as job search and networking, internship seeking, as well as receipt of quality job offers. Relatedly, studies could be conducted that measure the impact of the current paper's model and attributes on individuals' behavior in organizations like decision making and teamwork. It would be interesting to explore whether and to what degree employees with higher levels of proactive personality, core self-evaluation, grit and self-control frame and make decisions, as well as lead and work in teams. Additional research could explore how strategic independence relates to the facets of the five-factor model. From a pedagogical perspective, it would be interesting to better understand the impact professors and mentors can exert on Millennial students' inclinations towards strategic independence and how they can be improved to help the students be innovative and enterprising in transitioning toward successful careers. Future research could also explore the role that mentoring or coaching exerts in bringing out the best in these four positive traits in Millennials. Many young adults actively seek and receive academic and career-oriented mentoring while in college (Kram and Isabella 1985). Research has found that mentoring in a college environment can help students engage in planning that is related to college-career transitions (Crisp and Cruz 2009). This presents an excellent opportunity for mentors and coaches to help set Millennials on a trajectory of personal and professional success (Eby et al. 2008; Renn et al. 2014).

\section{Conclusions}

This study has focused on positive dispositional traits impacting Millennials. A significant amount of research attention has been paid to their negative traits, however we need to better understand the positive influences on their behaviors impacting their likelihood of long-term career success. In this spirit, the results of the current research study suggest that young adults who are proactive and self-controlled and possess grit, are more likely to be predisposed to make and adhere to plans in order to achieve long-term goals. It is precisely these types of young adults that are in the best position to change the negative stereotypes too often associated with Millennials and early career employees.

Acknowledgments: The authors received no funding or grants in support of this study or to publish it in open access. All sources of funding of the study should be disclosed. Please clearly indicate grants that you have received in support of your research work. Clearly state if you received funds for covering the costs to publish in open access.

Author Contributions: This research study is the result of a collaborative effort between the three authors. Each author contributed equally.

Conflicts of Interest: The authors declare no conflict of interest.

\section{References}

Abuhassan, Abedrahman, and Timothy C. Bates. 2015. Distinguishing effortful persistence from conscientiousness. Journal of Individual Differences 36: 205-14. [CrossRef] 
Arnett, Jeffrey Jensen. 2007. Suffering, selfish, slackers? Myths and reality about emerging adults. Journal of Youth Adolescence 36: 23-29. [CrossRef]

Barrick, Murray R., and Michael K. Mount. 1991. The Big Five personality dimensions and job performance: A meta-analysis. Personnel Psychology 44: 1-26. [CrossRef]

Bartnick, L. W., M. M. Kappelman, J. H. Berger, and Bernice Sigman. 1985. The value of the California Psychological Inventory in predicting medical-students career choice. Medical Education 19: 143-47. [CrossRef] [PubMed]

Bateman, Thomas S., and J. Michael Crant. 1993. The proactive component of organizational behavior: A measure and correlates. Journal of Organizational Behavior 14: 103-18. [CrossRef]

Binning, John F., and Gerald V. Barrett. 1989. Validity of personnel decisions: A conceptual analysis of the inferential and evidential bases. Journal of Applied Psychology 74: 478-94. [CrossRef]

Bowman, Nicholas A., Patrick L. Hill, Nida Denson, and Ryan Bronkema. 2015. Keep on truckin' or stay the course? Exploring grit dimensions as differential predictors of educational achievement, satisfaction, and intentions. Social Psychological and Personality Science 6: 639-45. [CrossRef]

Browne, Michael W., and Robert Cudeck. 1993. Alternative ways of assessing model fit. In Testing Structural Equation Models. Edited by Kenneth A. Bollen and J. Scott Long. London: Sage.

Brown, Douglas J., Richard T. Cober, Kevin Kane, Paul E. Levy, and Jarrett Shalhoop. 2006. Proactive personality and the successful job search: A field investigation with college graduates. Journal of Applied Psychology 91: 717-26. [CrossRef] [PubMed]

Burnette, Jeni L., Ernest H. O’boyle, Eric M. VanEpps, Jeffrey M. Pollack, and Eli J. Finkel. 2013. Mindsets matter: A meta-analytic review of implicit theories and self-regulation. Psychological Bulletin 139: 655-701. [CrossRef] [PubMed]

Byrne, Zinta S., Brian K. Miller, and Virginia E. Pitts. 2010. Trait entitlement and perceived favorability of human resources management practices in the prediction of job satisfaction. Journal of Business Psychology 25: 451-64. [CrossRef]

Chang, Chu-Hsiang, D. Lance Ferris, Russell E. Johnson, Christopher C. Rosen, and James A. Tan. 2012. Core self-evaluations: A review and evaluation of the literature. Journal of Management 38: 81-128. [CrossRef]

Cronbach, Lee J., and Paul E. Meehl. 1955. Construct validity in psychological tests. Psychological Bulletin 52: 281-302. [CrossRef] [PubMed]

Converse, Patrick D., Jaya Pathak, Anne Marie DePaul-Haddock, Tomer Gotlib, and Matthew Merbedone. 2012. Controlling your environment and yourself: Implications for career success. Journal of Vocational Behavior 80: 148-59. [CrossRef]

Costa, Paul T., and Robert R. McCrae. 1992. Revised NEO Personality Inventory (NEO-PI-R) and NEO Five-Factor Inventory (NEO-FFI) Professional Manual. Odessa: Psychological Assessment Resources.

Crisp, Gloria, and Irene Cruz. 2009. Mentoring college students: A critical review of the literature between 1990 and 2007. Research in Higher Education 50: 525-45. [CrossRef]

Duckworth, A. L. 2015. Research Statement, The Duckworth Lab. Available online: http:/ / sites/sas/upenn.edu/ duckworth (accessed on 31 March 2016).

Duckworth, Angela Lee, and Kelly M. Allred. 2012. Temperament in the classroom. In Handbook of Temperament, Edited by Rebecca L. Shiner and Marcel Zentner. New York: Guilford Press, pp. 627-44.

Duckworth, Angela, and James J. Gross. 2014. Self-control and grit: Related but separable determinants of success. Current Directions in Psychological Science 23: 319-25. [CrossRef] [PubMed]

Duckworth, Angela L., Christopher Peterson, Michael D. Matthews, and Dennis R. Kelly. 2007. Grit: Perseverance and passion for long-term goals. Personality Processes and Individual Differences 92: 1087-101. [CrossRef] [PubMed]

Eby, Lillian T., Tammy D. Allen, Sarah C. Evans, Thomas Ng, and David L. DuBois. 2008. Does mentoring matter? A multidisciplinary meta-analysis comparing mentored and non-mentored individuals. Journal of Vocational Behavior 72: 254-67. [CrossRef] [PubMed]

Fein, Erich C., and Howard J. Klein. 2011. Personality predictors of behavioral self-regulation: Linking behavioral self-regulation to five-factor model factors, facets, and a compound trait. International Journal of Selection and Assessment 19: 132-44. [CrossRef]

Freeman, Sunny. 2013. Millennials' Job Struggles: A Sign of Delayed Adulthood in the New Economic Reality. Huffington Post. May 21. Available online: http://www.huffingtonpost.ca/2013/05/21/millennials-jobstruggles_n_3312042.html (accessed on 18 November 2018). 
Fuller, Bryan, and Laura E. Marler. 2009. Change driven by nature: A meta-analytic review of the proactive personality. Journal of Vocational Behavior 75: 329-45. [CrossRef]

Gough, Harrison G. 1985. A work orientation scale for the California Psychological Inventory. Journal of Applied Psychology 70: 505-13. [CrossRef]

Gough, Harrison G. 1995. Career Assessment and the California Psychological Inventory. Journal of Career Assessment 3: 101-22. [CrossRef]

Gough, Harrison G. 1996. CPI Manual: Third Edition. Pal Alto: Consulting Psychologists Press.

Gough, Harrison G., and Kevin Lanning. 1986. Predicting grades in college from the California Psychological Inventory. Educational and Psychological Measurement 46: 205-13. [CrossRef]

Hair, Joseph F., William C. Black, Rolph E. Anderson, and Ronald L. Tatham. 1995. Multivariate Data Analysis, 4th ed. Englewood Cliffs: Prentice Hall.

Hall, Nathan C. 2012. Life in transition: A motivational perspective. Canadian Psychology 53: 63-66. [CrossRef]

Heckhausen, Jutta, Carsten Wrosch, and Richard Schulz. 2010. A Motivational Theory of Life-Span Development. Psychological Review 117: 32-60. [CrossRef] [PubMed]

Haynie, Jeffrey Joseph, C. Brian Flynn, and Shawn Mauldin. 2017. Proactive personality, core self-evaluations, and engagement: The role of negative emotions. Management Decision 55: 450-63. [CrossRef]

Henderson, J. M. 2014. Where Have All the Grownups Gone? Why 'Adulthood' as We Know It Is Dead. Forbes. September 22. Available online: http:/ / www.forbes.com (accessed on 18 November 2018).

$\mathrm{Hu}$, Li-tze, and Peter M. Bentler. 1999. Cutoff criteria for fit indexes in covariance structure analysis: Conventional criteria versus new alternatives. Structural Equation Modeling: A Multidisciplinary Journal 6: 1-55. [CrossRef]

Joo, Baek-Kyoo, Huh-Jung Hahn, and Shari L. Peterson. 2015. Turnover intentions: The effects of core self-evaluations, proactive personality, perceived organizational support, developmental feedback, and job complexity. Human Resource Development International 18: 116-30. [CrossRef]

Jöreskog, Karl G., and Dag Sörbom. 2006. LISREL 8.80 for Windows [Computer Software]. Lincolnwood: Scientific Software International, Inc.

Judge, Timothy A., and Robert D. Bretz. 1994. Political influence behavior and career success. Journal of Management 20: 43-65. [CrossRef]

Judge, Timothy A., and Charlice Hurst. 2007. Capitalizing on one's advantages: Role of core self-evaluations. Journal of Applied Psychology 92: 1212-27. [CrossRef] [PubMed]

Judge, Timothy A., Amir Erez, Joyce E. Bono, and Carl J. Thoresen. 2003. The core self-evaluations scale: Development of a measure. Personnel Psychology 56: 303-31. [CrossRef]

Kenny, Maureen E., David L. Blustein, Richard F. Haase, Janice Jackson, and Justin C. Perry. 2006. Setting the stage: Career development and the student engagement process. Journal of Counseling Psychology 53: 272-79. [CrossRef]

Kirby, Eric G., Robert Konopaske, and Susan L. Kirby. 2016. The impact of strategic independence and mentoring on entrepreneurial orientation: Exploring the propensity of Millennials to transition into full adulthood. International Review of Entrepreneurship 14: 1-20.

Kline, Paul. 2000. Handbook of Psychological Testing, 2nd ed. London: Routledge.

Kram, Kathy E., and Lynn A. Isabella. 1985. Mentoring alternatives: The role of peer relationships in career development. Academy of Management Journal 28: 110-32. [CrossRef]

Lapan, Richard T. 2004. Career Development across the K-16 Years: Bridging the Present to Satisfying and Successful Futures. Alexandria: American Counseling Association.

Long, James Scott. 1983. Covariance Structure Models: An Introduction to LISREL. Beverly Hills: Sage.

Lyons, Sean, and Lisa Kuron. 2014. Generational differences in the workplace: A review of the evidence and directions for future research. Journal of Organizational Behavior 35: 139-57. [CrossRef]

Marinova, Sophia V., Henry Moon, and Dishan Kamdar. 2013. Getting ahead or getting along? The two-facet conceptualization of conscientiousness and leadership emergence. Organization Science 24: 1257-76. [CrossRef]

McNall, Laurel A., and Jesse S. Michel. 2011. A dispositional approach to work-school conflict and enrichment. Journal of Business Psychology 26: 397-411. [CrossRef]

Mechler, Heather, and Brian Bourke. 2011. Millennial college students and moral judgment: Current trends in moral development indices. Journal of Organizational Moral Psychology 2: 27-38. 
Miller, Brian K., and Robert Konopaske. 2014. Dispositional correlates of perceived work entitlement. Journal of Managerial Psychology 29: 808-28. [CrossRef]

Moon, Henry. 2001. The two faces of conscientiousness: Duty and achievement striving in escalation of commitment dilemmas. Journal of Applied Psychology 86: 533-40. [CrossRef] [PubMed]

Paulus, Delroy L. 1986. Self-deception and impression management in test responses. In Personality Assessment via Questionnaire. Edited by A. Angleitner and J. S. Wiggins. New York: Springler-Verlag.

Podsakoff, Philip M., Scott B. MacKenzie, and Nathan P. Podsakoff. 2012. Sources of method biases in social science research and recommendations on how to control it. Annual Review of Psychology 63: 539-69. [CrossRef] [PubMed]

Renn, Robert W., Robert Steinbauer, Robert Taylor, and Daniel Detwiler. 2014. School-to-work transition: Mentor career support and student career planning, job search intentions, and self-defeating job search behavior. Journal of Vocational Behavior 85: 422-32. [CrossRef]

Reynolds, William M. 1982. Development of reliable and valid short forms of the Marlowe-Crowne Social Desirability Scale. Journal of Clinical Psychology 38: 119-25. [CrossRef]

Seibert, Scott E., Maria L. Kraimer, and J. Michael Crant. 2001. What do proactive people do? A longitudinal model linking proactive personality and career success. Personnel Psychology 54: 845-74. [CrossRef]

Smith, D. Brent, and Jill E. Ellingson. 2002. Substance versus style: A new look at social desirability in motivating contexts. Journal of Applied Psychology 87: 211-19. [CrossRef] [PubMed]

Stafford, Z. 2015. We Millennials lack a roadmap to adulthood. The Guardian. March 30. Available online: http:/ / www.theguardian.com (accessed on 18 November 2018).

Tangney, June P., Roy F. Baumeister, and Angie Luzio Boone. 2004. High self-control predicts good adjustment, less pathology, better grades, and interpersonal success. Journal of Personality 72: 271-322. [CrossRef] [PubMed]

Thomason, Stephanie J., Michael Weeks, H. John Bernardin, and Jeffrey Kane. 2011. The differential focus of supervisors and peers in evaluations of managerial potential. International Journal of Selection and Assessment 19: 82-97. [CrossRef]

Tough, Paul. 2013. How Children Succeed: Grit, Curiosity, and the Hidden Power of Character. Boston: Houghton Mifflin Harcourt.

Twenge, Jean M., and Stacy M. Campbell. 2008. Generational differences in psychological traits and their impact on the workplace. Journal of Managerial Psychology 23: 862-77. [CrossRef]

Wanberg, Connie R., and Joseph T. Banas. 2000. Predictors and outcomes of openness to changes in a reorganizing workplace. Journal of Applied Psychology 85: 132-42. [CrossRef] [PubMed]

West, Stephen G., John F. Finch, and Patrick J. Curran. 1995. Structural equation models with non-normal variables: Problems and remedies. In Structural Equation Modeling: Concepts, Issues, and Applications. Edited by Rick Hoyle. Thousand Oaks: Sage, pp. 56-75.

Ziegler, Matthias, Maximilian Knogler, and Markus Bühner. 2009. Conscientiousness, achievement striving, and intelligence as performance predictors in a sample of German psychology students: Always a linear relationship? Learning and Individual Differences 19: 288-92. [CrossRef]

(c) 2017 by the authors. Licensee MDPI, Basel, Switzerland. This article is an open access article distributed under the terms and conditions of the Creative Commons Attribution (CC BY) license (http:// creativecommons.org/licenses/by/4.0/). 